\section{P1-215 DEPRESSION IN DIFFERENT WELFARE STATE REGIMES IN EUROPE: THE ROLE OF ATTITUDES TOWARDS STATE RESPONSIBILITY FOR AN ADEQUATE STANDARD OF LIVING}

doi:10.1136/jech.2011.142976e.8

\section{P1-217 THE RELATIONSHIP BETWEEN LEISURE TIME PHYSICAL ACTIVITY, DIET CONTROL, SMOKING AND UTILISATION OF MEDICAL SERVICES IN DIABETES: RESULTS OF A NATIONAL COHORT IN TAIWAN}

doi:10.1136/jech.2011.142976e.10
${ }^{1,2} \mathrm{~K}$ Levecque, ${ }^{*}{ }^{2} \mathrm{R}$ Van Rossem, ${ }^{3} \mathrm{E}$ Ronda, ${ }^{4} \mathrm{~J}$ Love. ${ }^{1}$ Research Council Flanders,
Brussels, Belgium; ${ }^{2}$ Ghent University, Department of Sociology, Ghent, Belgium;
${ }^{3}$ Alicante University, Preventive Medicine and Public Health, Alicante, Spain; ${ }^{4}$ Robert Gordon University, Faculty of Health \& Social Care, Aberdeen, UK

Introduction Recent cross-national research by Levecque et al (Journal of Health and Social Behaviour, in press) has shown that the health effects of social experiences are attenuated, boosted or even reversed by the sociopolitical context. More specifically, it was found that the link between economic hardship and depression varies between different welfare state regimes in Europe.

Objectives Currently, we assess whether this variation in depressing effect is totally attributable to differences in welfare state arrangements or whether welfare state attitudes play a significant role as well. Is economic hardship more depressing when the individual considers the state as the main provider for an adequate standard of living, or is the risk of depression higher when emphasis is put on self-provision and individual responsibility?

Methods Analyses are based on data for 23 countries in the European Social Survey 2006-2007 ( $N=41686)$. Multilevel linear regressions are performed. Depression is measured using the Center for Epidemiologic Studies Depression Scale (CES-D 8).

Results We find that experiencing economic hardship is significantly more depressing for individuals who consider the state as the main responsible for providing an adequate standard of living. This pattern is observed in all welfare state regimes and remains significant when controlling for gender, age, having a partner, educational level, social support and locus of control.

Conclusion The link between economic hardship and depression is dependent on both structural welfare state arrangements and welfare state attitudes.

\section{P1-216 SURVIVING EXPERIENCE OR LIMITED FUTURE? A COMPARATIVE ANALYSIS OF ECONOMIC HARDSHIP AND DEPRESSION ACROSS THE ADULT LIFE SPAN IN DIFFERENT WELFARE STATE REGIMES IN EUROPE}

doi:10.1136/jech.2011.142976e.9

\footnotetext{
${ }^{1,2} \mathrm{~K}$ Levecque, ${ }^{*} \mathrm{R}$ Van Rossem. ${ }^{1}$ Research Council Flanders, Brussels, Belgium; ${ }^{2}$ Ghent University, Department of Sociology, Ghent, Belgium
}

In a study of depression in the general population living in the USA, Mirowsky and Ross (2001) found that economic hardship related depression decreases with age, suggesting increasing surviving experience as one gets older. We test whether this pattern can be generalised to other developed nations. Based on data for 23 countries taking part in the European Social Survey (2006-2007), multilevel analyses shows that the moderating role of age is in itself dependent on the socio-political context. The link between economic hardship and depression is not significantly different across the life course in the Nordic and Bismarckian regimes, it increases in the Southern and Eastern European countries and decreases in strength in the Anglo-Saxon welfare states. Our findings suggest that welfare state regimes play a significant role in attenuating, boosting or even reversing the health effects of social experiences such as economic hardship and ageing. Health knowledge gained through research that ignores the socio-political context might be limited in terms of generalisation
${ }^{1} \mathrm{C} L \mathrm{Li},{ }^{*}{ }^{1} \mathrm{~T}$ A Wang, ${ }^{1} \mathrm{~J} \mathrm{~T}$ Sheu, ${ }^{2} \mathrm{H}$ Y Chang. ${ }^{1}$ Department of Health Care Management, Chang Gung University, Kwei-Shan, Tao-Yuan, Taiwan; ${ }^{2}$ Division of Health Policy Research and Development, Institute of Population Health Sciences, National Health Research Institutes, Maoli, Taiwan

Introduction The aim of this study is to investigate whether leisure time physical activity, diet and smoking behaviours are associated with hospital utilisation in a nationally representative sample of adults with diabetes.

Methods We conducted a prospective study on persons aged 18 and above with self-reported physician-diagnosed diabetes $(\mathrm{N}=797)$ who participated in the National Health Interview Survey in Taiwan, 2001. A total of 596 participants had complete data for self-care behaviours and provided consent for data linkage and were successfully linked to the National Health Insurance claims data. Multiple logistic regression (occurrence of hospitalisation) and negative binomial regression (number of admissions and hospital bed days) were done to analyse the associations between self-care behaviours and hospital utilisation for any cause during 2002.

Results After adjusting for demographic characteristics, comorbidities, and diabetic related attributes, participants having a diet control was associated with fewer hospital bed days (incidence rate ratio $\mathrm{IRR}=0.57 ; 95 \% \mathrm{CI}$ [0.32 to 0.99$]$ ). Moreover, those participants reporting leisure time physical activity of $\geq 1000 \mathrm{kcal}$ per week had a significantly lower risk of hospitalisation $(\mathrm{OR}=0.35 ; 95 \% \mathrm{CI}[0.16$ to 0.77], fewer admissions (IRR $=0.31 ; 95 \% \mathrm{CI}$ [0.16 to 0.58]) and fewer hospital bed days (IRR $=0.17 ; 95 \%$ CI [0.07 to 0.37]) compared with inactive individuals.

Conclusion Our findings suggest that the promotion for adults with diabetes in performing their self-care behaviours, especially exercising and having a diet control may have economic benefits. However, more research is needed to explore the underlying obstacles to engaging in self-care behaviours among people with diabetes.

\section{P1-218 IS INFORMAL CHILD CARE ASSOCIATED WITH CHILDHOOD OBESITY? EVIDENCE FROM THE HONG KONG'S “CHILDREN OF 1997" BIRTH COHORT}

doi:10.1136/jech.2011.142976e.11

S L Lin, ${ }^{*}$ G M Leung, L L Hui, T H Lam, C M Schooling. The University of Hong Kong, Hong Kong, China

Introduction In western populations, informal child care is associated with childhood obesity. However, in western populations, informal child care and childhood obesity are associated with lower socioeconomic position (SEP), making these observations vulnerable to residual confounding. In this situation, evidence from non-western developed settings can be valuable.

Methods We used multivariable linear and logistic regression to estimate the association of child care at 6 months, 3 years, 5 years and 11 years with body mass index (BMI) z-score and overweight (including obesity) at 11 years in a large population-representative Hong Kong Chinese birth cohort, "Children of 1997", comprising 88\% of births in April and May 1997. We also assessed if the associations varied with sex or SEP.

Results Of the original 8327 cohort members, 7933 are alive, participating and living in Hong Kong. At approximately 11 years, 6796 had clinically assessed BMI. Higher SEP was associated with informal care. Informal care at each of 3,5 or 11 years was 